The Journal of Laryngology \& Otology

http://journals.cambridge.org/JLO

Additional services for The Journal of Laryngology \& Otology:

Email alerts: $\underline{\text { Click here }}$

Subscriptions: $\underline{\text { Click here }}$

Commercial reprints: Click here

Terms of use : $\underline{\text { Click here }}$

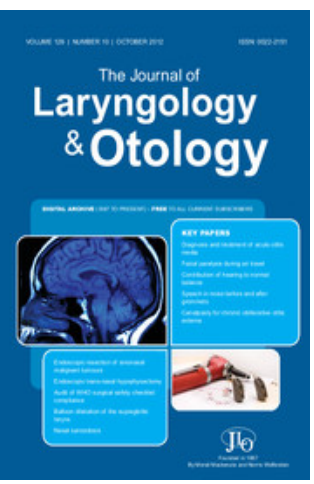

\title{
Post-laryngectomy neopharyngeal diverticulae
}

C. Hartley, S. R. Saeed and W. T. Farrington

The Journal of Laryngology \& Otology / Volume 108 / Issue 06 / June 1994, pp 479 - 483

DOI: 10.1017/S002221510012715X, Published online: 29 June 2007

Link to this article: http://journals.cambridge.org/abstract_S002221510012715X

How to cite this article:

C. Hartley, S. R. Saeed and W. T. Farrington (1994). Post-laryngectomy neopharyngeal diverticulae. The Journal of Laryngology \& Otology, 108, pp 479-483 doi:10.1017/S002221510012715X

Request Permissions : $\underline{\text { Click here }}$ 


\title{
Post-laryngectomy neopharyngeal diverticulae
}

\author{
C. Hartley, F.R.C.S., S. R. Saeed, F.R.C.S., W. T. Farrington, F.R.C.S.
}

\begin{abstract}
Four cases with a neopharyngeal diverticulum following total laryngectomy are presented. Each patient required surgery for complications directly related to the pouch. The relevance of these diverticulae is discussed with reference to their aetiology, complications and management.
\end{abstract}

Key words: Laryngectomy, complications; Diverticulum; Laser surgery; Pharyngeal diseases

\section{Introduction}

Diverticulae of the neopharynx are common following total laryngectomy, occurring in 35 to 100 per cent of cases (Davis et al., 1982; Nayar et al., 1984). Despite this frequency, they seldom give rise to symptoms (Al-Saati et al., 1993). We present case histories of four patients, all of whom required surgical treatment for complications directly related to such diverticulae. The aetiology, management and potential complications of neopharyngeal diverticulae are discussed.

\section{Case reports}

\section{Case I}

A 54-year-old man underwent a course of radical radiotherapy for $\mathrm{a}_{2}$ glottic carcinoma. Eighteen months later a laryngectomy was performed for symptoms attributable to severe radionecrosis. The pharyngeal defect was closed in three layers without a formal cricopharyngeal myotomy. Post-operative recovery was unremarkable.

Over the next six months the patient developed increasing problems with late regurgitation of undigested food. Pharyngoscopy was performed which revealed no resistance to the passage of a size $38 \mathrm{FG}$ bougie. A pouch at the level of the vallecula was noted and felt to be responsible for the symptoms. A barium swallow confirmed the presence of a marked anterior diverticulum (Figure 1). The patient therefore underwent laser division of the bar of tissue between the pouch and the pharynx. Unfortunately, the extent of tissue removal was inadequate and a small symptomatic pouch remained. Further operative division of the party wall was therefore undertaken with good effect.

\section{Case 2}

A 55-year-old man underwent a course of radical radiotherapy for a $T_{3}$ carcinoma of the larynx. On three occa-

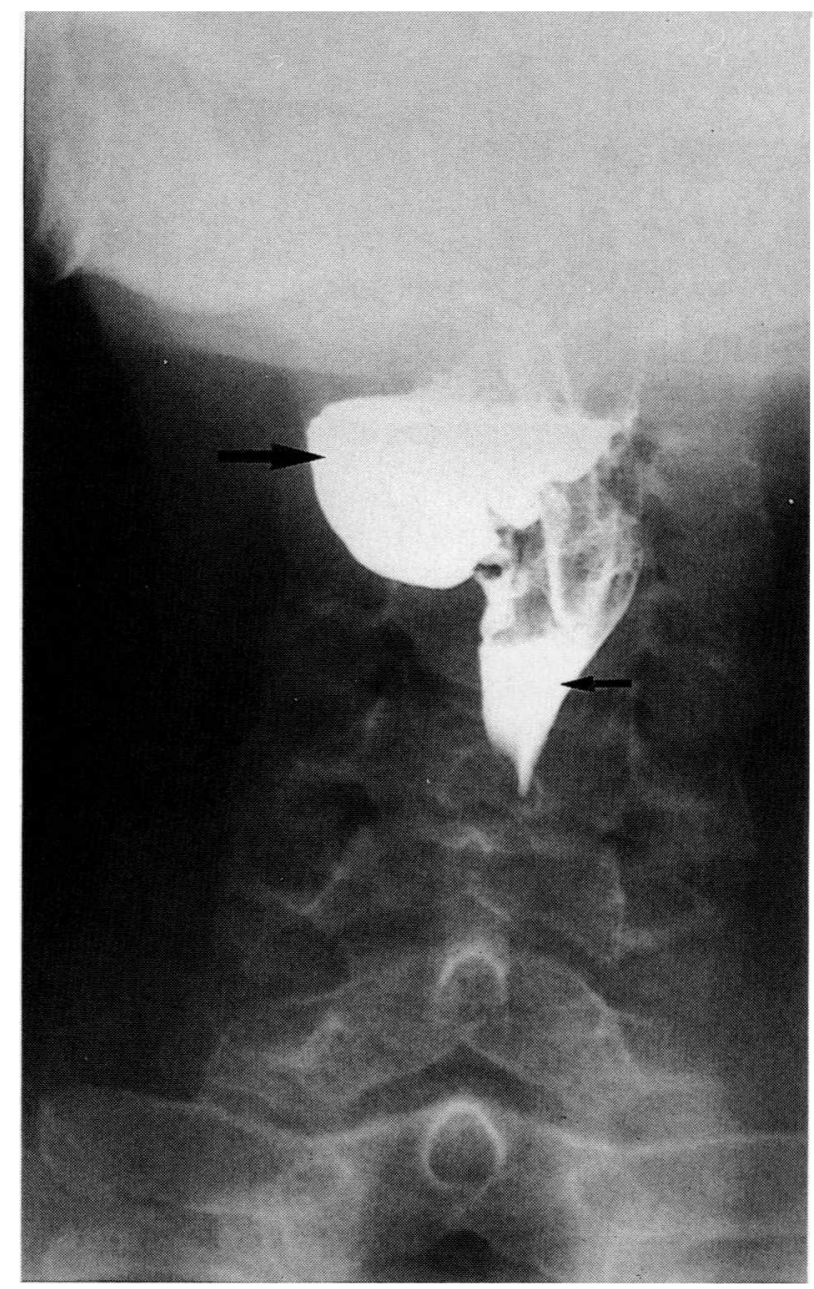

FIG. 1

Barium swallow (anterior oblique view) demonstrating neopharyngeal diverticulum (large arrow) and neopharynx (small arrow) 

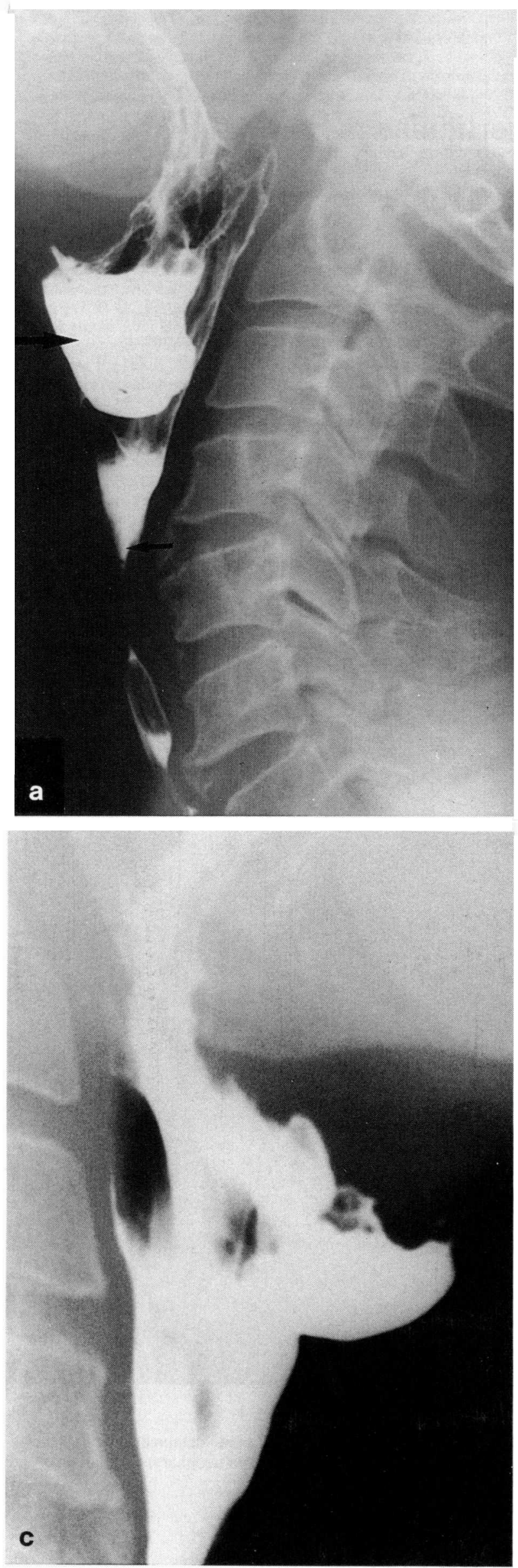

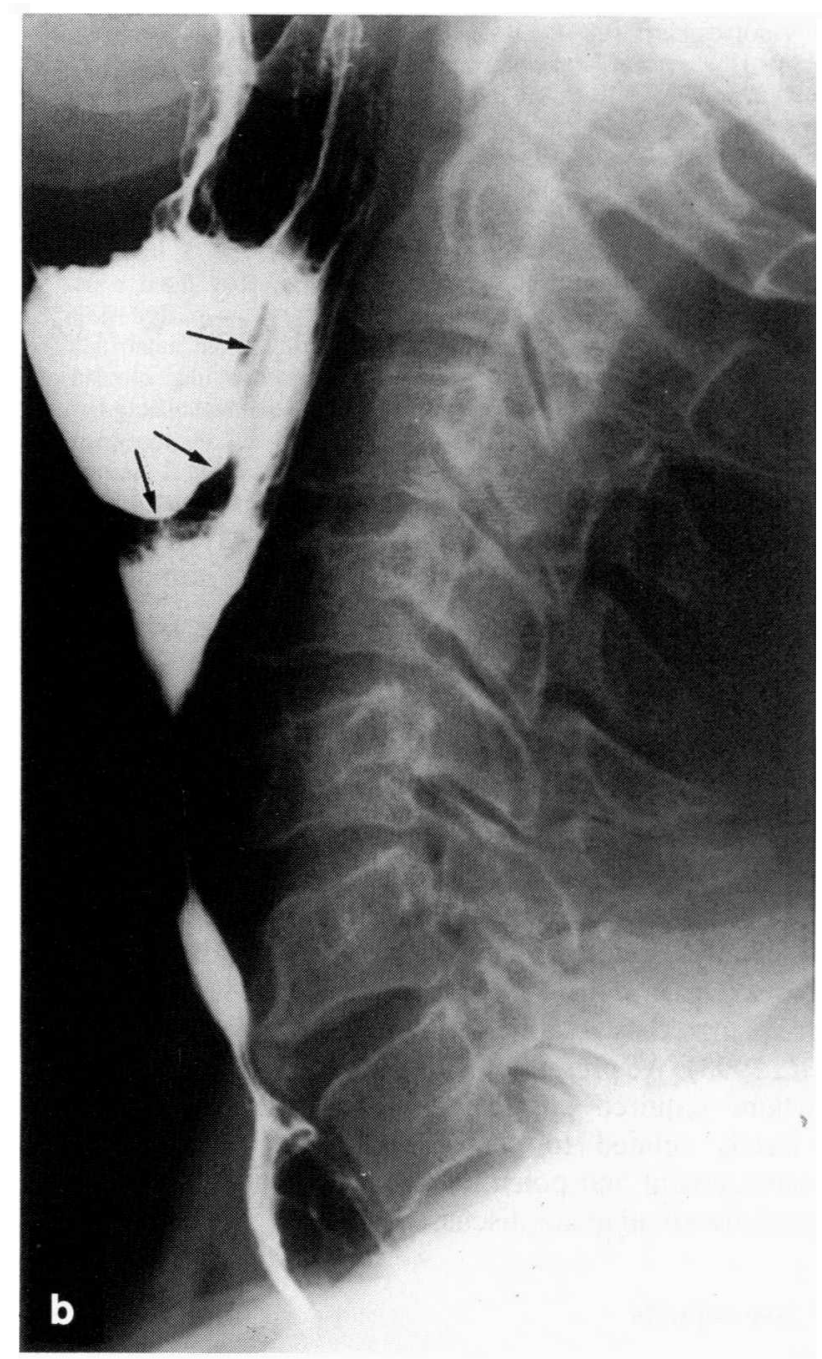

FIG. 2

(a) Barium swallow (lateral oblique view) demonstrating anterior pouch (large arrow) and high pharyngeal stricture (small arrow); (b) barium swallow (lateral view) demonstrating bar of tissue (arrows) between the pouch and the pharyngeal lumen; (c) post-operative barium swallow (lateral view) demonstrating absence of the pouch. 


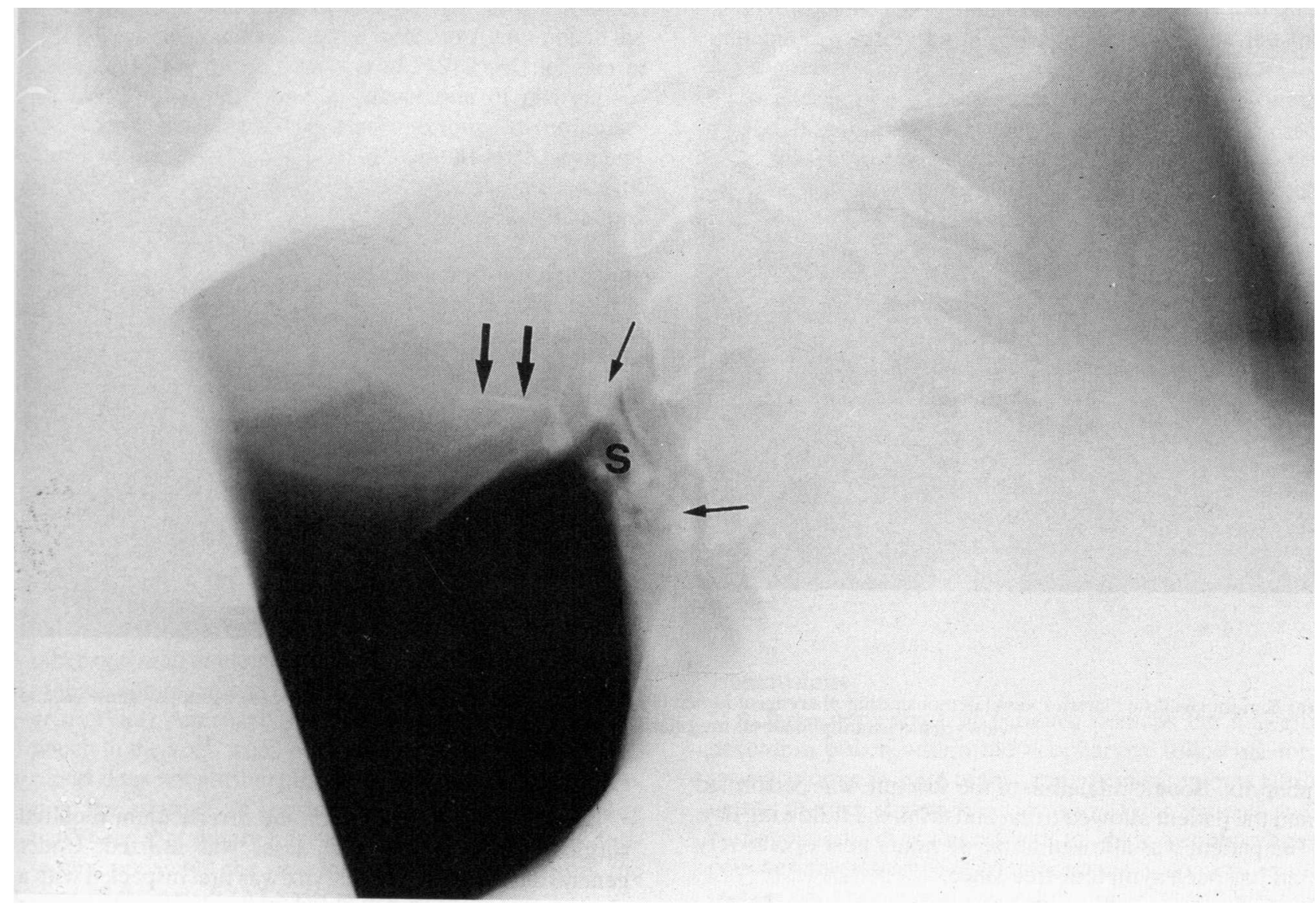

FIG. 3

Lateral soft tissue cervical X-ray demonstrating radiopaque foreign body (large arrows) and widespread calcification (small arrows) around the stoma $(S)$.

sions following this, a barium swallow was performed for the symptom of persistent dysphagia. These confirmed the presence of a sliding hiatus hernia and benign lower oesophageal stricture, which was dilated by flexible upper GI endoscopy three years after the initial radiotherapy. The following year, total laryngectomy was undertaken for severe radionecrosis. A cricopharyngeal myotomy and two-layer vertical pharyngeal closure were performed, as was primary insertion of a Provox ${ }^{\circledR}$ valve. Two weeks post-operatively, the patient developed a left parastomal pharyngocutaneous fistula. This closed spontaneously within three weeks. Ten months following laryngectomy, the patient experienced increasing dysphagia and underwent pharyngoscopy and bougie dilatation of a pharyngeal stricture to $38 \mathrm{FG}$. However, the dysphagia persisted and a barium swallow was repeated. This revealed a marked anterior pharyngeal diverticulum at the base of the tongue (Figure 2a,b). Re-operation with laser division of the party wall between the diverticulum and the pharynx resulted in relief of the patient's difficulty on swallowing. Some six months later however, a barium swallow was again performed for recurrent dysphagia. This demonstrated that the difficulty in swallowing was due to a distal oesophageal stricture and that the pouch had resolved with laser treatment (Figure 2c).

\section{Case 3}

A 52-year-old man underwent a total laryngectomy fol- lowing failure of radiotherapy for a $T_{2}$ carcinoma of the larynx. A three-layer vertical closure was performed. Two weeks post-operatively, the patient developed a rightsided pharyngocutaneous fistula which required delayed primary closure 12 weeks later.

Fourteen years later, the patient presented acutely with a sharp foreign body within the pharynx (Figure 3). Rigid endoscopy confirmed a right lateral neopharyngeal diverticulum within which was lodged a spicule of bone. The bone was removed and, given the absence of a history of dysphagia or regurgitation, further treatment was not undertaken.

\section{Case 4}

A 61-year-old woman underwent a total laryngectomy with hyoid preservation seven years after radical radiotherapy for a $\mathrm{T}_{2}$ carcinoma of the larynx. A cricopharyngeal myotomy was not undertaken and the pharynx was closed in three layers. Three years later, a barium swallow was performed for increasing dysphagia. This demonstrated a right-sided pharyngeal diverticulum (Figure 4a), below which was a smooth-walled stricture. As there was the suspicion of a filling defect within the pouch (Figure 4b), pharyngoscopy was performed, but this revealed no abnormality. The saggital bar of tissue extending from the base of the tongue to the right posterior pharyngeal wall was divided using the $\mathrm{CO}_{2}$ laser to provide distal continuity between the diverticulum and neo- 


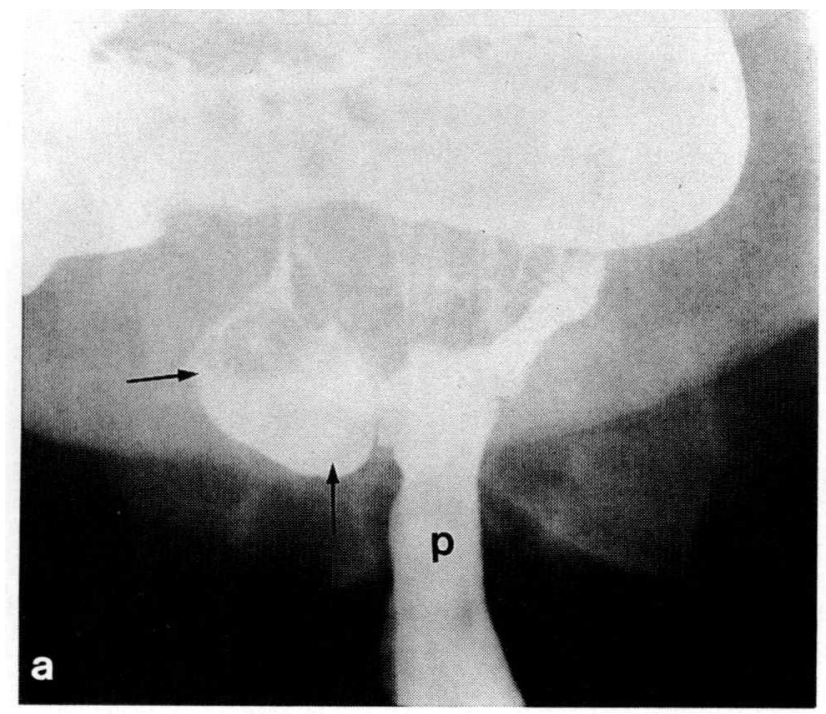

Fig. 4

(a) Barium swallow (anterior view) demonstrating pharyngeal lumen (P) and lateral pharyngeal pouch (arrows); (b) barium swallow (lateral view) demonstrating mucosal irregularity within the neopharyngeal pouch.

pharynx. Bougie dilatation of the stricture was performed and the patient allowed to eat and drink the following day. The patient was allowed home 48 hours post-operatively and has been symptom-free since.

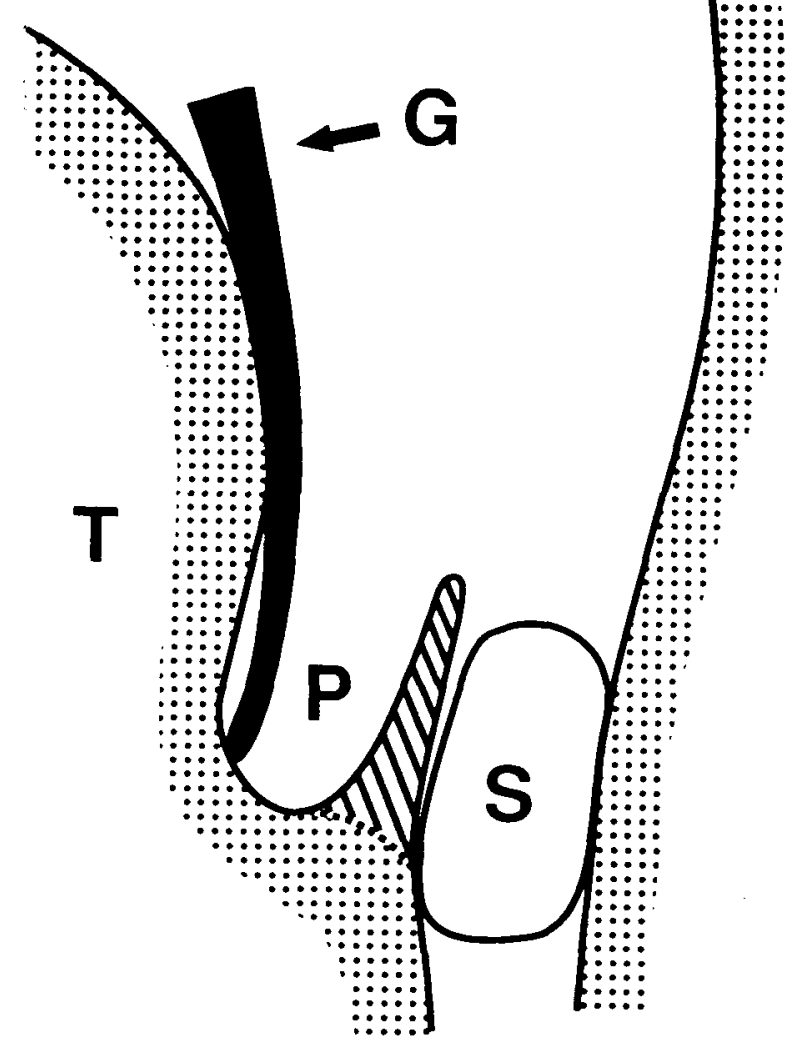

Fig. 5

Line drawing of operative technique lateral view: blade of Boyle Davis gag $(G)$ inserted into the pouch $(P)$; tongue base $(T)$, pseudoepiglottis (shaded) and swab (S) within the pharynx, protecting the posterior pharyngeal wall from laser injury.

\section{Operative technique}

In the three cases in which the diverticulum required surgical treatment, the $\mathrm{CO}_{2}$ laser was utilized. Under general anaesthesia, the pharynx was first inspected with a pharyngoscope and the pouch then displayed using a Boyle-Davis gag. (It is important to select a blade of sufficient length to insert deep into the pouch, to allow visualization of the entire extent of the party wall between the pouch and the lumen of the pharynx). Using the $\mathrm{CO}_{2}$ laser set on $10 \mathrm{~W}$ continuously, this bar of tissue was excised flush with the deep extent of the pouch. To protect the posterior pharyngeal wall from laser injury, a moist swab was placed in the pharynx posterior to the bar of tissue to be excised (Figure 5). The excised tissue was submitted for histological examination.

A slight modification to this technique was required for the treatment of lateral diverticuluae. The blade of the gag was inserted into the lumen of the neopharynx, alongside the party wall which was then divided as described above using the laser. The patient was allowed to eat and drink the following day.

\section{Discussion}

The existence of neopharyngeal diverticuluae following laryngectomy is well documented (Kritchener et al., 1963; Davis et al., 1982; Nayar et al., 1984). Such diverticuluae may be demonstrated by direct or contrast examination, with the posterior wall of the diverticulum being termed a 'pseudo-epiglottis'. The aetiology of these pouches is however far from clear. Incoordination of the constrictor muscles post-operatively has been advanced as one explanation (Kritchener et al., 1963), as has the type of closure. In a study evaluating the hypopharynx of 28 post-laryngectomy patients by barium swallow, the pseudo-epiglottis was present in all cases in which vertical closure had been performed, compared to 67 per cent of those in whom a T-shaped closure had been undertaken. 
Complications including dysphagia, stricture formation and pharyngocutaneous fistulae were more common in the vertical closure group (Davis et al., 1982). Kritchener et al. (1963) also described an association of pharyngocutaneous fistulae with post-laryngectomy diverticulae. However, in a further study of 20 patients after laryngectomy, there was no association between the presence of the pseudo-epiglottis and post-operative complications (Nayar et al., 1984).

These studies demonstrate that post-laryngectomy diverticulae occur in 35 to 100 per cent of patients. It is highly likely therefore that the frequency of their existence is related to altered pharyngeal physiology postoperatively. Using manofluorography, it has been shown that the swallowing mechanism of all laryngectomees is altered post-operatively. The absence of a negative pressure within the pharyngo-oesophageal (PE) segment results in patients having to generate higher propulsive pressures than normal using the tongue as a piston. This raised pressure within the neopharynx may explain the high incidence of diverticulae and pharyngocutaneous fistulae post-laryngectomy. The presence of a stricture or other obstructive element would further increase the risk of these complications (McConnel et al., 1986; McConnel et al., 1988). A recent case report describes the finding of a pouch in the sixth week post-laryngectomy. Although the report does not attribute the pouch development to infection, the stigmata of sepsis were clearly present. It may have been that timely intervention with intravenous antibiotics prevented the development of a fistula from the apex of the pouch (Al-Saati et al., 1993).

In our series, all patients had received radiotherapy whilst two patients developed early pharyngocutaneous fistulae. In both, the pouch was in such a position as to be at the proximal end of the fistula track. In the patient with a laterally based fistula, a lateral pouch developed. The patient with a parastomal leak developed an anterior pouch. In this patient significant distal stricturing was present. A stricture was also present in one other patient. In three of our cases, closure was vertical, whilst no record of the method of closure was found in the remaining case. Cricopharyngeal myotomy was performed in one patient.

In the light of the available evidence, we suggest that post-laryngectomy diverticulae are pulsion diverticulae. Factors which increase the distal PE resistance such as oedema, absence of a cricopharyngeal myotomy or stricture, may contribute to the high incidence of such pouches. The relationship between such diverticulae, sepsis and pharyngocutaneous fistulae may also be causal.

Complications of a neopharyngeal pouch as with other diverticulae include dysphagia, late regurgitation of undigested food and foreign body sensation. Foreign body impaction may also occur as illustrated by Case 3 . Carcinoma within a neopharyngeal diverticulum, unlike carcinoma within a Zenkers diverticulum has not, to our knowledge, been described yet although it is a theoretical risk (Burton and Lund, 1990; Saunders et al., 1993).

The treatment of post-laryngectomy pouches has only recently been described. As in our series, the diverticulum was visualized using a Boyle-Davis gag. The bar of tissue was however divided using Dohlman's apparatus (Al Saati et al., 1993). Alternatively, a staple gun or laser excision can be used as for pharyngo-oesophageal diverticulae (Benjamin and Innocenti, 1991; Martin-Hirsch and Newbegin, 1993). Our experience suggests that most patients can safely be allowed to eat and drink the following day.

As all four of our cases were seen within a three-month period, it is probable that many more symptomatic cases exist than is generally recognized. Dysphagia however, may be attributed to an associated pharyngeal stricture and dilatation performed with partial symptomatic relief. In addition, as these diverticulae occur soon after laryngectomy (Davis et al., 1982), the patient may accept any alteration of swallowing as a normal post-operative phenomenon. These factors combined with the high incidence of post-laryngectomy dysphagia strongly suggest that patients with this symptom following laryngectomy should be investigated further. Endoscopic or radiological examination may be performed, but there is a poor correlation between these two methods in the assessment of these diverticulae (Nayar et al., 1984): this may be because instrumentation distorts the anatomy. Barium swallow is therefore recommended as the investigation of choice.

\section{Conclusions}

A large percentage of patients, perhaps the majority, develop a pouch within the neopharynx following total laryngectomy. In spite of this, reports of symptoms attributable to such diverticulae are rare. Four patients with complications directly related to their neopharyngeal pouches are presented. The importance of contrast examination in the investigation of upper gastrointestinal symptoms following laryngectomy is emphasized.

\section{References}

Al-Saati, A., Mitchell, D. B., Toynton, S., O'Connor, A. F. (1993) Post-laryngectomy diverticulum - a case report. Journal of Laryngology and Otology 107: 46-48.

Benjamin, B., Innocenti, M. (1991) Laser treatment of pharyngeal pouch. Australian and New Zealand Journal of Surgery 61: 909-913.

Burton, M. J., Lund, W. S. (1990) Pharyngeal pouch carcinoma: two unusual cases. Journal of Laryngology and Otology 104: $821-823$.

Davis, R. K., Vincentt, M. E., Shapshay, S. M., Strong, M. S. (1982) The anatomy and complications of ' $T$ ' versus vertical closure of the hypopharynx after laryngectomy. Laryngoscope 92: 16-22.

Kritchener, J. A., Scatliff, J. H., Dey, F. L., Shedd, D. P. (1963) The pharynx after laryngectomy - changes in its structure and function. Laryngoscope 73: 18-33.

Martin-Hirsch, D. P., Newbegin, C. J. R. (1993) Autosuture GIA gun: a new application in the treatment of hypopharyngeal diverticulae. Journal of Laryngology and Otology 107: 723-725.

McConnel, F. M., Mendelsohn, M. S., Logemann, J. A. (1986) Examination of swallowing after total laryngectomy using manofluorography. Head and Neck Surgery 9: 3-12.

McConnel, F. M., Cerenko, D., Mendelsohn, M. S. (1988) Dysphagia after total laryngectomy. Otolaryngologic Clinics of North America 21: $721-726$.

Nayar, R. C., Sharma, V. P., Arora, M. M. (1984) A study of the pharynx after laryngectomy. Journal of Laryngology and Otology 98: $807-810$.

Saunders, M. W., Murty, G . E., Bradley, P. J. (1993) Pharyngeal pouch carcinoma. Ear, Nose and Throat Journal 72: 149-150.

Address for correspondence:

Mr C. Hartley,

39 Beech Road,

Cale Green,

Stockport,

Cheshire SK3 8HD 